\title{
Post-Earthquake Fires and Performance of Firefighting Activity in the Early Stage in the 1995 Great Hanshin Earthquake
}

\author{
AI SEKIZAWA \\ National Research Institute of Fire and Disaster \\ Ministry of Home Affairs \\ 3-14-1, Nakahara, Mitaka, Tokyo 181, Japan
}

\begin{abstract}
A number of simultaneous post-earthquake fires occurred in the 1995 Great Hanshin earthquake. In terms of fire incidence in regions heavily affected by the earthquake, fires occurred almost evenly in proportion to the ratio of damaged structures even other than Nagata-ward in Kobe city where major conflagrations were concentrated. This fact indicates that most of the postearthquake fires were suppressed in their early stage by fire brigades. The reason for concentration of very large fires in Nagata-ward is not only high incidence of fires there, but also higher risks of fire spread attributed to city configuration, i.e. ratio of wooden structures and average distance between adjacent buildings in that region. In addition, the performance of firefighting activity in the early stage is another key factor to the difference of fire damage by region. When the number of initial fires exceeds the number of engines available, extremely large fire sizes result in urban areas.
\end{abstract}

KEYWORDS : post-earthquake fire, conflagration, city configuration, firefighting activity.

\section{INTRODUCTION}

Several crucial lessons were learned from the 1994 Northridge earthquake in Los Angeles. One year later, the Great Hanshin earthquake ( officially referred to as "the Off-South Hyogo Prefecture Earthquake" by the Japan Meteorological Agency :JMA ) happened revealing them to us again at 5:46 a.m. on January 17,1995. It can be said the worst scenario, to which we did not have enough time to apply the lessons from the Northridge earthquake to mitigate potential risk in Japan.

Even though the degrees of damage were different, these two earthquakes under large modern cities have quite a few similarities in terms of structural damages, disruption of lifelines, pattern of fire outbreaks, some barriers to firefighting activity such as damaged fire hydrants, and so on. However, it is also important to point out a significant difference in the damage of the two earthquakes, that is, occurrence of conflagrations in city areas. In the Northridge earthquake, 
no conflagration took place except in special places like mobile home parks. On the other hand, there were such fires in Kobe. The conditions in the city areas, such as building coverage and width of streets, are considered as ones of the most significant reasons for this difference in the risk of fire spread. Because, if a number of fires occur simultaneously beyond the firefighting resources in zones having high dense wooden structures, some fires would inevitably spread.

The Hanshin earthquake left us with a significant task: how to improve means of fire spread prevention in city areas with zones having very packed wooden structures in Japan. In this paper, the features of ignitions, spread of post-earthquake fires, and the performance of firefighting activity in the early stage in the Hanshin earthquake are discussed based on the analyses using the data of fires provided by fire departments in affected regions.

\section{POST-EARTHQUAKE FIRES}

\section{Ignition of Post-Earthquake Fires in Time Order}

FIGURE 1 shows the frequency of ignitions of post-earthquake fires in time order after the Hanshin earthquake on January 17 in affected regions. 109 fires in Kobe city and 96 fires in cities other than Kobe occurred after the Hanshin earthquake on that day. From FIGURE 1, 89 fires (43\%) out of all the fires on January 17 started by 6:00 a.m., 14 minutes after the main shock at 5:46 a.m. As a result, the situation can be called as "multiple simultaneous ignitions just after an earthquake". The degree of concentration of post-earthquake fires in the 14 minutes after the earthquake is larger in Kobe city than in other cities.

On the other hand, although the frequency of fires decreased gradually with time lapse on January 17, 87 fires (42\%) started in 4 hours from 6:00 a.m. to 10:00 a.m., and some other fires started several hours later after the earthquake. Actually, this profile of occurrence of fires in time order is very similar to the one[1] observed in the 1994 Northridge earthquake in Los Angeles.

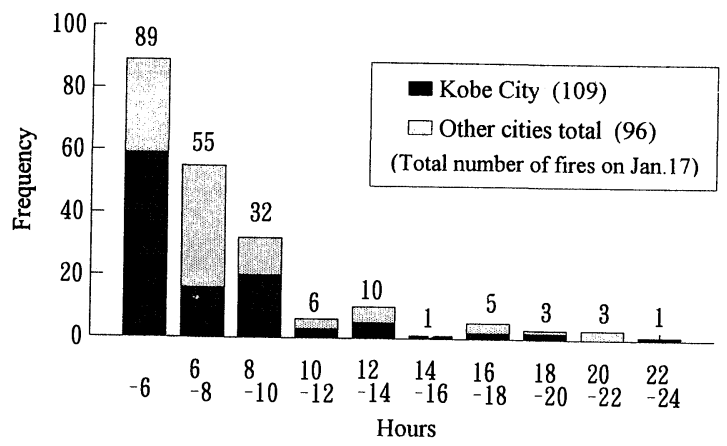

FIGURE 1 Frequency of Post-earthquake Fires in Time Order on January 17 after the 1995 Hanshin Earthquake. 


\section{Causes of Fire Ignition}

FIGURE 2 shows the frequency of post-earthquake fires by cause of ignition in time order for all regions. In this figure, "electrical causes" stands for fires caused by malfunction of electrical apparatuses and wires mostly in occasions of recovery of electricity supply in damaged houses. When excluding fires whose causes are unknown, most fires were derived from "gas leakage or gas apparatuses" and "other fire apparatuses or chemicals" rather than "electrical causes" for the fires that occurred by 6:00 a.m. shortly after the main shock. However, with time lapse after 6:00 a.m., the proportion of "gas leakage or gas apparatuses" and "other fire apparatuses or chemicals" decreased and, in stead, the proportion of electrical causes increased and became main after 7:00 a.m. in connection with the recovery of electricity supply.

This pattern of causes of ignition in time order was also observed[1][2] in the 1994 Northridge earthquake. For this pattern of fire ignitions, the Los Angeles City Fire Department indicated that the first wave was formed by a number of fires starting simultaneously just after the main shock which were mainly caused by gas leakage and the second wave was formed by sporadic fires which were mostly electrical fires derived from the recovery of electricity supply in collapsed structures. The same situation of fire ignitions occurred again in the Hanshin earthquake. The similarities in the patterns of occurrence and causes of fire ignitions on both earthquakes should be remarked and studied further.

\section{Incidence of Post-earthquake Fires by Region}

FIGURE 3 shows the locations[3] of fires from January 17 to January 19 in Hyogo prefecture. In terms of fire incidence in regions heavily impacted by the earthquake, fires occurred almost uniformly even other than Nagata-ward in Kobe city where large fires were concentrated. The incidence of fires following the earthquake is fairly well in proportion to the ratio of damaged structures as seen in FIGURE 4. These results are reasonable because structural damage

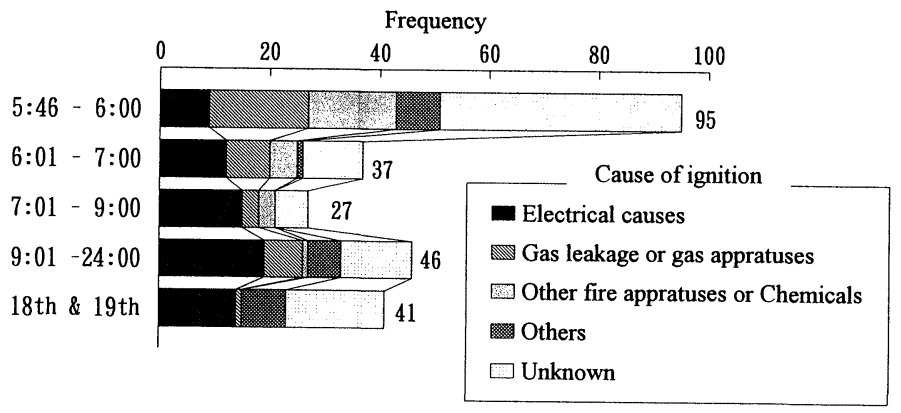

FIGURE 2 Frequency of Post-earthquake Fires by Cause of Ignition in Time Order. (All Regions) 
relates greatly to disruption of gas pipes and damage of electrical wires or apparatuses resulting in potential risk of fire ignition derived from gas leakage and malfunction of electrical apparatuses and wires in occasions of recovery of electricity supply as indicated by Murozaki[4].

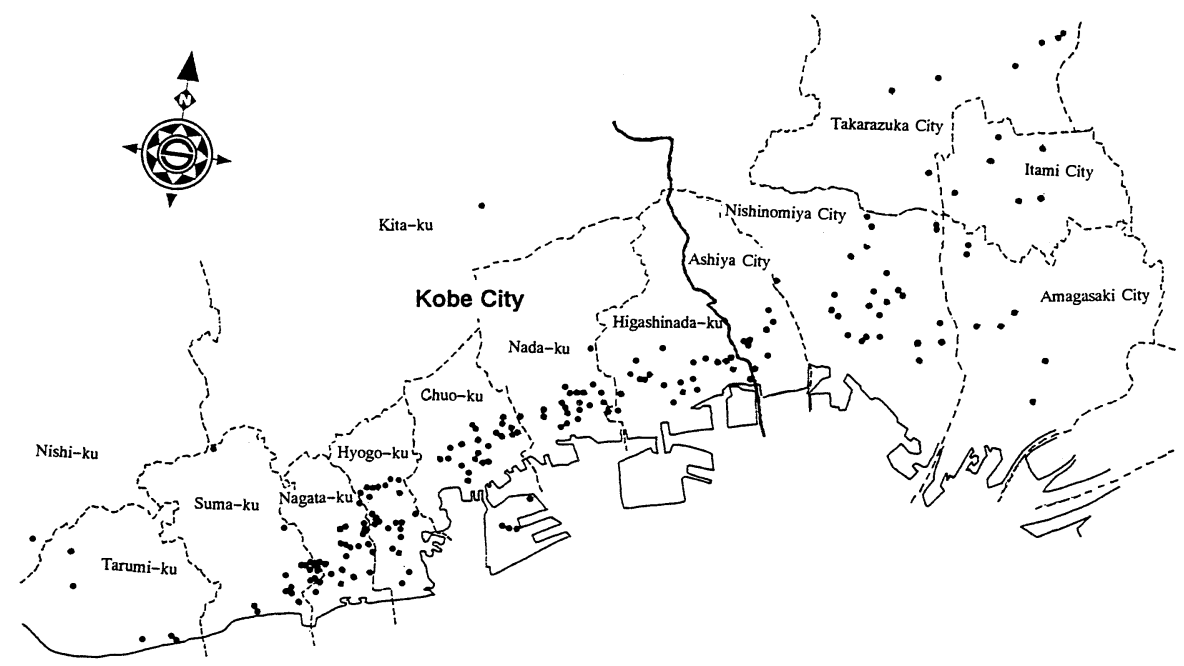

FIGURE 3 Locations of Post-earthquake Fires in Hyogo Prefecture.

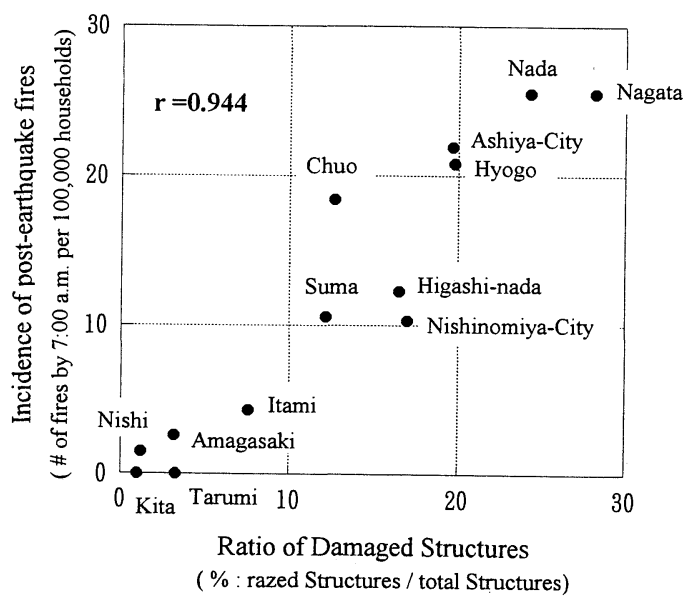

FIGURE 4 Relation between Incidence of Post-earthquake Fires and Ratio [5] of Damaged Structures by Region. 
TABLE 1 Numbers and Percentages of Post-earthquake Structure Fires by Size by Region.

(Note : Fires for January 17th - 19th. The data as of November, 1995)

\begin{tabular}{|c|c|c|c|c|c|c|c|c|}
\hline \multirow{2}{*}{$\begin{array}{l}\text { Wards for Kobe } \\
\text { and } \\
\text { cities }\end{array}$} & \multicolumn{4}{|c|}{ Fire Size* } & \multirow{2}{*}{$\begin{array}{l}\text { Total } \\
\text { number of } \\
\text { fires by } \\
\text { region }\end{array}$} & \multirow{2}{*}{$\begin{array}{l}\text { Total } \\
\text { number of } \\
\text { burned } \\
\text { structures }\end{array}$} & \multirow{2}{*}{$\begin{array}{l}\text { Average of } \\
\text { burned } \\
\text { structures } \\
\text { per fire }\end{array}$} & \multirow{2}{*}{$\begin{array}{l}\text { Incidence of } \\
\text { post-earthquake } \\
\text { fires** }\end{array}$} \\
\hline & $\begin{array}{l}\mathrm{A} \\
\end{array}$ & ${ }^{B}(\%)$ & ${ }^{C}(\%)$ & $\begin{array}{l}\mathrm{D} \\
\end{array}$ & & & & \\
\hline Higashi-nada & $0(0.0)$ & $6(30.4)$ & $5(13.1)$ & $12(56.5)$ & 23 & 367 & 16.0 & 31.5 \\
\hline Nada & $1(5.3)$ & $8(42.1)$ & $6(31.6)$ & $4(21.0)$ & 19 & 559 & 29.4 & 37.3 \\
\hline Chuo & $0(0.0)$ & $5(18.2)$ & $2(13.6)$ & $19(68.2)$ & 26 & 107 & 4.1 & 53.1 \\
\hline Hyogo & $2(9.1)$ & $7(27.3)$ & $4(22.7)$ & $10(40.9)$ & 23 & 1. 038 & 45.1 & 43.4 \\
\hline Nagata & $7(36.4)$ & $8(31.8)$ & $2(9.1)$ & $5(22.7)$ & 22 & 4,814 & 218.8 & 43.1 \\
\hline Suma & $1(6.3)$ & $5(18.7)$ & $4(31.2)$ & $6(43.8)$ & 16 & 432 & 27.0 & 24.2 \\
\hline Tarumi & $0(0.0)$ & $0(0.0)$ & $0(0.0)$ & $6(100.0)$ & 6 & 6 & 1.0 & 6.9 \\
\hline Kita & $0(0.0)$ & $0(0.0)$ & $1(100)$ & $0(0.0)$ & 1 & 2 & 2.0 & 1.3 \\
\hline Nishi & $0(0.0)$ & $0(0.0)$ & $0(0.0)$ & $1(100.0)$ & 1 & 1 & 1.0 & 1.5 \\
\hline Kobe City Total & $11(9.0)$ & $39(26.1)$ & $24(18.7)$ & $63(46.3)$ & 137 & 6.312 & 53.5 & 24.0 \\
\hline Nishinomiya City & $0(0.0)$ & $1(2.6)$ & $12(31.6)$ & $25(65.8)$ & 38 & 90 & 2.4 & 24.4 \\
\hline Ashiya City & $0(0.0)$ & $0(0.0)$ & $4(30.8)$ & $9(69.2)$ & 13 & 23 & 1.8 & 40.6 \\
\hline Amagasaki City & $0(0.0)$ & $1(12.5)$ & $1(12.5)$ & $6(75.0)$ & 8 & 15 & 1.9 & 4.1 \\
\hline Osaka City & $0(0.0)$ & $0(0.0)$ & $2(13.3)$ & $13(86.7)$ & 15 & 19 & 1.3 & 1.4 \\
\hline Other cities & $0(0.0)$ & $0(0.0)$ & $1(3.4)$ & $28(96.6)$ & 29 & 1 & 1.0 & --- \\
\hline Sum Total & $11(4.6)$ & 41 (17.1) & $44(18.3)$ & $144(60.0)$ & 240 & 7,504 & 31.3 & - \\
\hline
\end{tabular}

* Fire size A: Burned more than $10,000 \mathrm{~m}^{2}$
B: Burned in 1,000 $\mathrm{m}^{2} \sim 10,000 \mathrm{~m}^{2}$
** Fires by January 19 per 100,000 households
C: Beyond an origin structure but less than $1,000 \mathrm{~m}^{3}$ D: Confined to an origin structure

\section{Fires by Size by Region}

TABLE 1 shows numbers and percentages of post-earthquake structure fires from January 17 to January 19 by size and by region. The total number of fires in all regions by January 19 is 240, 137 of which are in Kobe, but other 103 are in cities other than Kobe. However, the eleven very large fires having burned area more than $10,000 \mathrm{~m}^{2}$ were concentrated around Nagata-ward in Kobe. And, out of 52 large fires having burned area more than $1,000 \mathrm{~m}^{2}$ in the table, 50 fires occurred in Kobe except for the two fires in Nishinomiya city and Amagasaki city. In terms of average burned structures per fire as an index of average fire size by region, the cities other than Kobe have less than 2.5. Also, less damaged regions in Kobe like Tarumi-ward, Kita-ward, and Nishi-ward have 2.0 or less. Only south east part of Kobe city had many large fires.

These facts indicate that most of the post-earthquake fires were suppressed in their early stage by fire brigades, specially in the cities other than Kobe. Therefore, the concentration of large fires around Nagata-ward was not simply because of the high incidence of fires, but also because of the higher risks of fire spread attributed to city configuration, i.e. ratio of wooden structures and average distance between adjacent buildings, etc. in those regions. (See FIGURE 5 and FIGURE 6 ) Although the values of ratio of wooden structures and average 
distance between adjacent buildings as well as incidence of post-earthquake fires for Nishinomiya city are similar to those for Suma-ward, Nishinomiya city has far smaller average fire size than Suma-ward has. The reason for this lower average fire size for Nishinomiya city should be explained by other factors such as firefighting performance as discussed later. It is also true that wind velocity is generally one of very influential factors to fire spread.

However, in the regions heavily impacted by the Hanshin earthquake, the wind velocity on January 17 was quite moderate, mostly under $4.0 \mathrm{~m} / \mathrm{s}$ [8] which did not make so much difference of impact to fire spread potential by region. In this paper, therefore, the author does not refer to wind velocity hereafter as a key factor of fire spread damage by region for this specific case of the Hanshin earthquake.

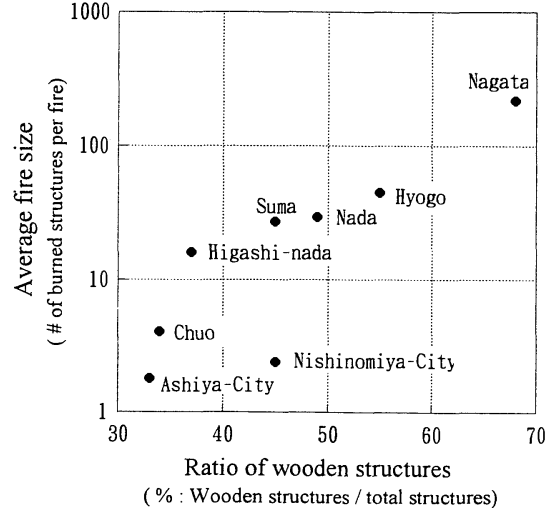

FIGURE 5 Relation between Average Fire Size and Ratio [6] of Wooden Structures by Region.

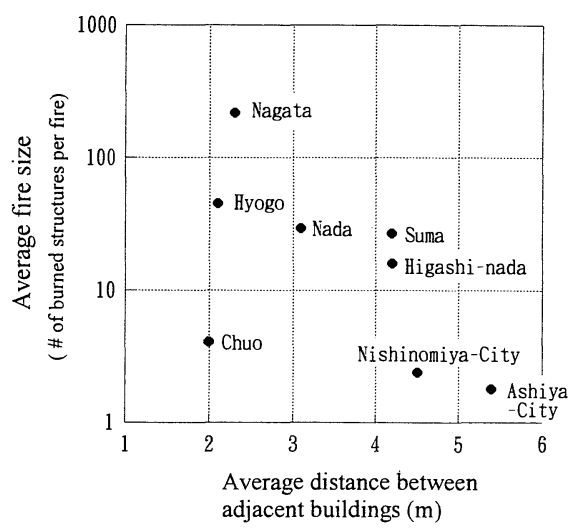

FIGURE 6 Relation between Average Fire Size and Average Distance[7] between Adjacent Buildings by Region.

FIGURE 7 shows the proportion of structure fires by extent of fire spread in time order up to January 19 for Kobe city (a) and cities other than Kobe (b) respectively. As for Kobe, only a third of fires that started by 6:00 a.m. on January 17 were single fires which were confined to a structure of fire origin. Further, about a half of fires by 6:00 a.m. spread to be large fires having burned area more than $1,000 \mathrm{~m}^{2}$. Although the proportion of larger size fires other than single fires becomes smaller with time lapse, still $39 \%$ of fires that started during January 18 to 19 spread beyond a fire origin structure. This result indicates that fire brigades could not control post-earthquake fires in their early stage specially for the fires that started shortly after the earthquake and this situation continued to some extent until January 19 in Kobe. By contrast, as for the cities other than Kobe, the percentage of single fires for the fires by 6:00 a.m. is quite high (73\%) and large fires having burned area more than $1,000 \mathrm{~m}^{2}$ occupy only $3 \%$. Although the percentage of single fires increases gradually with time lapse, there is not so much change among time periods in FIGURE 7. In other words, fire brigades functioned fairly well against post-earthquake fires in the regions other than Kobe even in the period shortly after the earthquake. 
The similar tendency as mentioned above is also seen in FIGURE 8 which shows the proportion of post-earthquake structure fires by extent of fire spread by type of structure of a fire origin. From FIGURE 8, it is clearly found that the type of structure of a fire origin affects the extent of fire spread even though the degree of influence differs between the regions of Kobe city (a) and cities other than Kobe (b). For the reason of this difference between the regions (a) and (b), average distance from a fire origin structure to adjacent structures and performance of firefighting activity in the early stage are considered. Anyway, it should be remarked that fire-resistive structures like reinforced concrete functioned significantly to mitigate fire spread from a fire origin structure to adjacent structures. There were many fires that started from reinforced concrete structures in both Kobe city (49\%) and cities other than Kobe (35\%) as seen in FIGURE 8. The fire damage would have been much more serious, if the proportion of number of such fires from fire-resistive structures had been smaller.

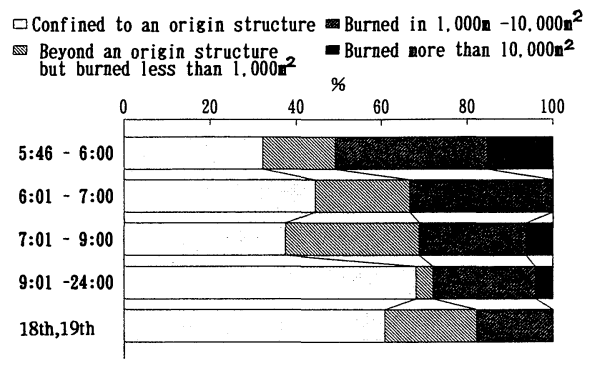

(a) for Kobe City

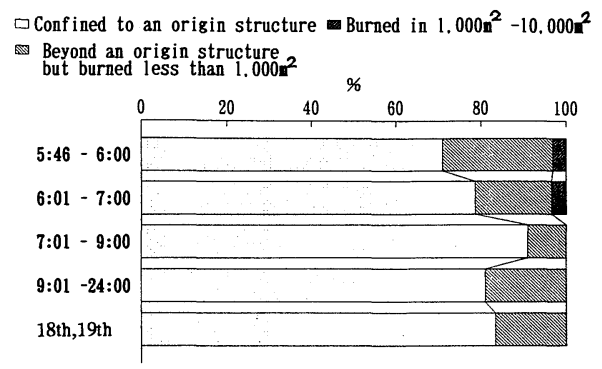

(b) for cities other than Kobe

FIGURE 7 Proportion of Number of Post-earthquake Structure Fires by Extent of Fire Spread in Time Order.

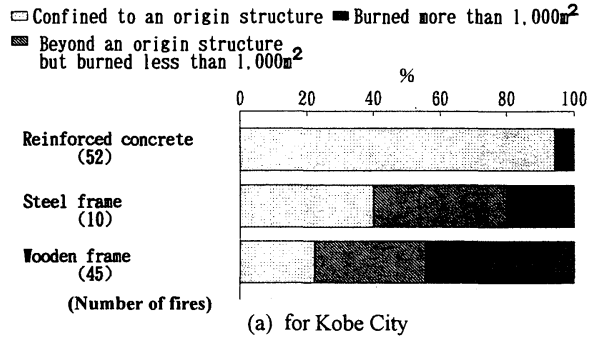

(a) for Kobe City

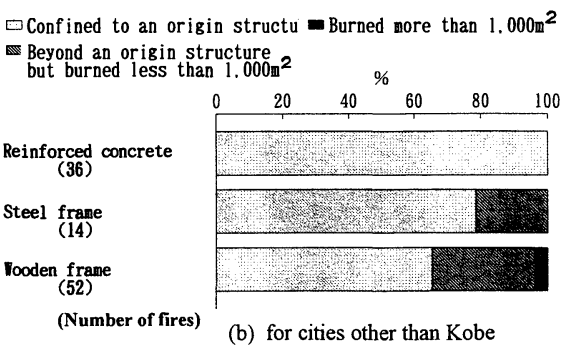

(b) for cities other than Kobe

FIGURE 8 Proportion of Post-earthquake Structure Fires by Extent of Fire Spread by Type of Structure of a Fire Origin Structure. 


\section{FIRE FIGHTING ACTIVITY IN THE EARLY STAGE}

Besides city configuration and type of structure of a fire origin discussed previously, firefighting activity in the early stage of fire growth is another key factor that affects risk of fire spread to adjacent structures. In this section, we discuss about the performance of firefighting activity against post-earthquake fires in the Hanshin earthquake and also the critical condition of whether fire brigades are able to control those fires or not in their early stage.

\section{The Performance of Firefighting Activity in the Early Stage}

FIGURE 9 shows the data of cumulative frequency of both fire ignitions and suppressed fires at periodical time on January 17 for Kobe city (a) and cities other than Kobe (b). For both regions (a) and (b), final cumulative number of ignitions of post-earthquake fires on January 17 is not so different from each other. However, the gap between cumulative frequency of fire ignitions and suppressed fires at each time, i.e. number of unsuppressed fires at each time, is quite large between regions (a) and (b) especially during initial several hours after the earthquake. The data indicates that firefighting activity in cities other than Kobe was fairly effective to control post-earthquake fires in their early stage and then the fire brigades could cope with sequential fires one after another. On the other hand, the fire brigades in Kobe could not control post-earthquake fires so effectively in their early stage that they had to fight against sequential fires as additional burden besides remaining unsuppressed fires. In this sense, the performance of firefighting activity in the early stage of fire growth of simultaneous post-earthquake fires is very influential to subsequent results of fire damage.

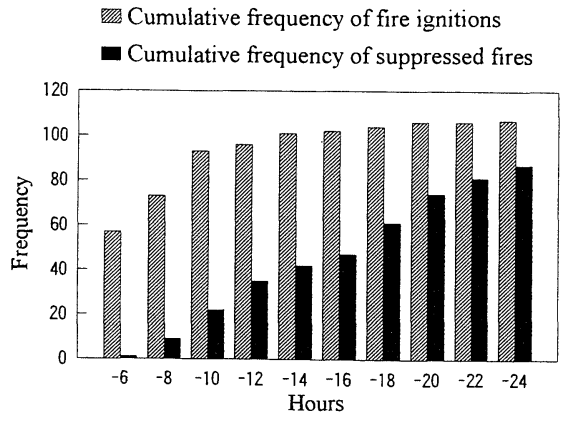

(a) for Kobe City

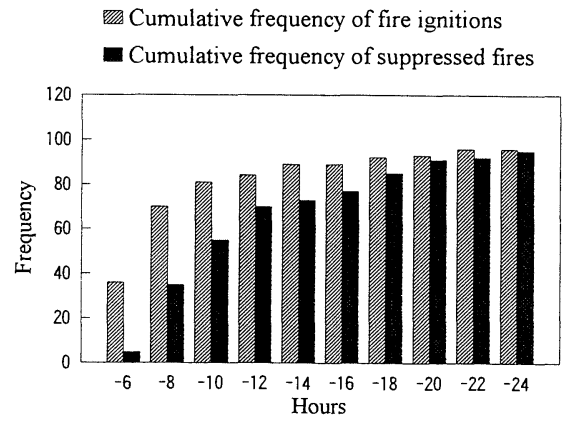

(b) for cities other than kobe

FIGURE 9 Cumulative Frequency of Fire Ignitions and Suppressed Fires in Time Order.

TABLE 2 provides the data of post-earthquake structure fires in Kobe city and other cities by 7:00 a.m. on January 17 and the conditions of fire brigades in the initial stage by region. In Kobe city, by 7:00 a.m., there were 63 simultaneous fires. Actually, the number of fires was more than the number of fire engines[9], 40. Regarding three wards in Kobe, Tarumi, Kita, 
and Nishi, there was only one fire so that the fire stations there had much capacity left in the initial stage to cope with fires in their jurisdictions, because firefighting operation of each fire station in the initial stage at an earthquake is usually concentrated upon districts within its own jurisdiction. Therefore, the three wards should be excluded when the firefighting capability of Kobe city in the initial stage is considered. Then, they had only 28 fire engines, which were ready, against 62 simultaneous fires. In other words, as simply calculated, they could not cope with at least 34 fires. In TABLE 2 , the proportion of large fires which burned more than $1,000 \mathrm{~m}^{2}$ as well as average of burned structures per fire is large in the regions where the number of fires by 7:00 a.m. exceeds fire engines initially dispatched. This fact indicates that the extent of fire damage at an earthquake depends basically upon the balance of number of simultaneous fires and firefighting resources such as number of fire engines ready to be dispatched, if water supply like cisterns is at least secured.

The contents of firefighting activity in Ashiya city are worth close looking. Ashiya city is populated about 87,000 and had seven simultaneous fires following the earthquake which is as high incidence as that of Nagata-ward in Kobe. Although fire hydrants were not available, the fire brigades put out fires so successfully that five fires burned only one building for each

TABLE 2 Post-earthquake Structure Fires by 7:00 a.m. and the Conditions of Fire Brigades in the Initial Stage by Region.

\begin{tabular}{|c|c|c|c|c|c|c|}
\hline \multirow{2}{*}{ City or Ward } & \multicolumn{3}{|c|}{ Structure fires by $7: 00$ a.m. Jan. 17} & \multirow{2}{*}{$\begin{array}{l}\text { Number of fire } \\
\text { engines initially } \\
\text { dispatched at } \\
\text { the earthquake }\end{array}$} & \multirow{2}{*}{$\begin{array}{l}\text { Damaged to } \\
\text { fire hydrants }\end{array}$} & \multirow{2}{*}{$\begin{array}{l}\text { Average of } \\
\text { burned } \\
\text { structures } \\
\text { per fire } \\
\text { by } 7: 00 \text { a.m. }\end{array}$} \\
\hline & $\begin{array}{l}\text { Total } \\
\text { number }\end{array}$ & $\begin{array}{l}\text { Fires spread } \\
\text { over } 1000 \mathrm{~m}^{\prime} \\
\text { burned area }\end{array}$ & $\begin{array}{l}\text { Single fires } \\
\text { (\# of } \mathrm{RC} \\
\text { buildings) }\end{array}$ & & & \\
\hline Kobe City Total & 63 & $34(54 \%)$ & $17(15)$ & 40 & mostly Damaged & 72.1 \\
\hline Higashinada & 9 & $4(44 \%)$ & $3(3)$ & 5 & used up to 2 hours & 22.2 \\
\hline Nada & 13 & $7(54 \%)$ & $2(2)$ & 4 & Damaged & 30.4 \\
\hline Chuo & 9 & $2(22 \%)$ & $6(5)$ & 5 & Partially damaged & 5.0 \\
\hline Hyogo & 11 & $6(55 \%)$ & $3(2)$ & 5 & Damaged & 88.6 \\
\hline Nagata & 13 & $11(85 \%)$ & $2(2)$ & 5 & Damaged & 225.2 \\
\hline Suma & 7 & $4(57 \%)$ & $1(1)$ & 4 & Damaged & 42.7 \\
\hline Tarum i & 0 & $0(0 \%)$ & 0 & 4 & Damaged & $-^{* *}$ \\
\hline Kita & 0 & $0(0 \%)$ & 0 & 5 & unknown & $-^{* *}$ \\
\hline Nishi & 1 & $0(0 \%)$ & $1(1)$ & 3 & Damaged & 1.0 \\
\hline Nishinomiya City & 16 & $2(13 \%)$ & $7(3)$ & $21^{*}$ & Damaged & 3.4 \\
\hline Ashiya City & 7 & $0(0 \%)$ & $5(4)$ & $8^{*}$ & Damaged & 1.6 \\
\hline Amagasaki City & 5 & $1(20 \%)$ & $3(1)$ & $16^{*}$ & Damaged & 2.6 \\
\hline Osaka City & 11 & $0(0 \%)$ & $9(7)$ & 23 & Undamaged & 1.4 \\
\hline Toyonaka City & 3 & $0(0 \%)$ & $3(1)$ & $9^{*}$ & Undamaged & 1.0 \\
\hline
\end{tabular}

* The number includes fire engines of volunteer fire corps.

* * There is no fire by 7:00 a.m. 
and that none burned more than $1,000 \mathrm{~m}^{2}$. They distinguished all the simultaneous fires in their early stage, which number was close to that of fire engines initially dispatched. Although four of seven fires started fortunately in fire-resistive structures, there are two other reasons pointed out: the cooperation of the volunteer fire corps who possess fire engines and the adequate use of two rivers running through the city.

\section{Critical Condition in Performance of Firefighting Activity}

If a number of simultaneous fires occur far beyond firefighting resources in the initial stage, there would be naturally unattended and/or unsuppressed fires to spread further. By contrast, if the number of fires is small enough for fire brigades to control, there would be no seriously spread fire even in an earthquake situation. Therefore, the capability of firefighting activity against simultaneous post-earthquake fires naturally has certain critical condition according to the level of resources such as fire engines, manpower, and water supply system etc. in each jurisdiction of a fire department. The question is what is the critical condition of whether fire brigades are able to control simultaneous post-earthquake fires or not in their early stage.

FIGURE 10 shows the relation between average fire size and average number of fire engines with pump function initially dispatched per fire for the fires by 7:00 a.m. after the Hanshin earthquake by region. It is clearly found that the average fire size increases steeply as the average number of fire engines dispatched per fire goes down below 1.0. On the other hand, when the average number of fire engines dispatched per fire is larger than 1.0, the average fire size does not change so much and is at most 3.4 in Nishinomia city. Therefore, the critical level of performance of fire fighting activity in terms of average number of fire engines initially dispatched per fire seems to be around 1.0.

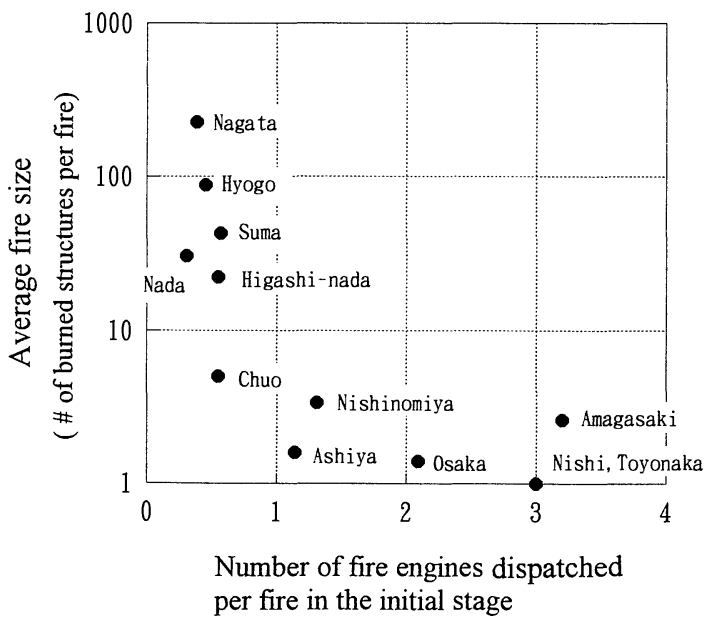

FIGURE 10 Relation between Average Fire Size and Number of Fire Engines Dispatched per Fire in the Initial Stage for Fires by 7:00 a.m. 
The data in FIGURE 10 include fires from fire-resistive structures such as reinforced concrete, most of which are single fires, so the critical level must be moved to be higher than 1.0, if only fires from wooden structures are concerned.

\section{CONCLUDING REMARKS}

The incidence and causes of ignitions, factors of fire spread, and the performance of firefighting activity by the fire brigades for post-earthquake fires in the Great Hanshin Earthquake are discussed based on the analyses using the data of fires provided by fire departments in suffered regions. The results are summarized as follows;

1) The incidence of fires following the earthquake is in proportion to the ratio of damaged structures resulting in large proportion of fire causes such as gas leakage related fires and malfunction of electric apparatuses and wires in connection with the recovery of electricity supply. The pattern of ignitions in time order and causes of fires are very similar to those observed in the Northridge earthquake.

2) The reason for concentration of large fires around Nagata-ward in Kobe city is not only high incidence of fires, but also higher risks of fire spread attributed to the city configuration, i.e. ratio of wooden structures and average distance between adjacent buildings as well as crucial lack of fire engines against fires in the initial stage in those regions.

3) The critical level of performance of fire fighting activity in terms of average number of fire engines initially dispatched per fire seems to be around 1.0.

In the last, as observed in Kobe City at the time of the Hanshin earthquake, it might possibly happen again in future earthquakes that some fires are not suppressed in their early stage and grow up to be conflagrations. The point is how we prevent fire spread to minimize fire damage, but the solution should not be looked for only in firefighting capability which has limitation. In order to prevent a conflagration, fire-proof city planning such as road widening and construction of fire-resistive structures etc. is significantly necessary besides reinforcement of firefighting resources.

\section{ACKNOWLEDGMENTS}

The author highly appreciates the courtesy of Kobe City Fire Department and many other fire departments in affected regions who cooperated in making the data of post-earthquake fires and thereby enabled me to do this work.

\section{REFERENCES}

1. Scawthorn, C., Cowell, A., Ward, W., Borden, F., Collier, C., Hoffman, F. and Harwood,T.: "Fire-related Aspects of the January 17, 1994 Northridge Earthquake", Chapter 8, Spectra, Earthquake Engineering Research Institute, Oakland CA, 1995.

2. Sekizawa, A.: "Report on the Post-earthquake Fires and Firefighting Activity in the 1994 Northridge Earthquake", Journal of Japan Association for Fire Science and Engineering, Vol.45 No.4, pp. 19-26, 1995. 
3. Sekizawa, A.: "Post-earthquake Fires and Firefighting Activity in the 1995 Great Hanshin Earthquake", Science Journal KAGAKU, Vol.66 No.2, 132-134, Iwanami-Shoten, 1996.

4. Murozaki, Y.: "Overview of the Fire Damage", in Proceedings of the Symposium on Lessons from Fire Damage in the 1995 Southern Hyogo Prefecture Earthquake, pp. 3-6, Fire Safety Division of Architectural Institute of Japan, 1995.

5. Takeuchi, Y.: "Earthquake Disasters and Countermeasures against Them in the Regions in Seismic Intensity VII in JMA Scale", in Proceedings of the Symposium on what happened in the 1995 Southern Hyogo Prefecture Earthquake, 1995.

6. Kajima Corporation: "Damage by Region", in The Second Report on the Damage in the 1995 Southern Hyogo Prefecture Earthquake, pp.180-184, 1995.

7. Building Research Institute: "Disaster Preparedness and Fire Protection", in The Interim Report on the Damage Investigation in the 1995 Southern Hyogo Prefecture Earthquake, pp. 495-541, 1995.

8. National Research Institute of Fire and Disaster: "The Weather Condition at The Hanshin Earthquake", in The Prompt Report on the Investigation of Conflagrations in Kobe city in the 1995 Southern Hyogo Prefecture Earthquake, pp. 69-86, 1995.

9. Kobe City Fire Department: "Activities by Fire Station", in The Report on the Firefighting Activities in the Great Hanshin Earthquake, pp.41-106, 1995. 